\title{
La cuestión del espacio / en el límite de la literatura
}

\author{
The Issue of the Space / in the Boundary of Literature
}

A questão do espaço / na fronteira da literatura

\section{Mónica Bernabé}

\author{
UNIVERSIDAD NACIONAL DE ROSARIO, ARGENTINA
}

Profesora Adjunta de Literatura Iberoamericana II en la Escuela de Letras de la Facultad de Humanidades y Artes de la Universidad Nacional de Rosario. Doctora en Letras por la Universidad de Buenos Aires. Coordinadora Académica de la Maestría en Estudios Culturales (CEI - UNR). Publicó Vidas de artista. Bohemia y dandismo en Mariátegui, Valdelomar y Eguren (Rosario-Lima, Beatriz Viterbo-Instituto de Estudios Peruanos, 2006), El abrigo de aire. Ensayos sobre literatura cubana en colaboración con Antonio José Ponte y Marcela Zanin, (Beatriz Viterbo, 2001) y artículos y ensayos en volúmenes colectivos y revistas académicas. Correo electrónico: monicabernabe02@gmail.com

\footnotetext{
Artículo de Reflexión

El presente artículo es una Conferencia ofrecida en las II fornadas Estudiantiles de Escritura e Investigación "Cuando escribir es investigar" en la Escuela de Letras de la Facultad de Humanidades y Artes de la UNR y forma parte de mi trabajo de investigación realizado durante el período de Beca financiada por John Simon Guggenheim Memorial Foundation que próximamente será editado por la Editorial de la misma facultad. Documento accesible en línea desde la siguiente dirección: http://revistas.javeriana.edu.co
} 


\section{Resumen}

El artículo parte de una serie de preguntas sobre el estado actual del campo de los estudios literarios para poder rediseñar sus objetos atendiendo a formas del pasado que retornan en ciertas escrituras del presente: ¿será posible atender a las incumbencias de nuestra disciplina (entendida como la construcción de un campo de saber con un conjunto de métodos específicos) sin quedar cautivos en los exclusivos territorios de la autonomía? ¿Cómo dar cuenta de la coyuntura que necesariamente atraviesa toda experiencia sensible sin reducirla a diferencias de género, étnicas o sociales? ¿Cómo darle respuesta, en nuestros de estudios, al desafío que constituyen las nuevas tecnologías?

Palabras clave: estudios literarios; vanguardias; tecnologías; desigualdades; documento

\section{Resumen}

The article begins with a series of questions about the current state of the field of literary studies with the purpose to redesign their object taking into account forms of the past that returning in certain writings of the present: Is it possible to meet the competencies of our discipline (defined as the construction of a field of knowledge with a set of specific methods) without being captive in the exclusive territories of autonomy? How to account for the situation that necessarily crosses the whole sensory experience without reducing it to differences gender, ethnic or social? How to respond, in our studies, the challenge posed by new technologies?

Keywords: Literature Studies, Vanguards; Technologies; Inequalities; Document

\section{Resumen}

$\mathrm{O}$ artigo começa com uma série de perguntas sobre o estado atual do campo dos estudos literários, a fim de reformular os seus objetos, considerando que existem formas do passado voltando em alguns escritos contemporâneos: é possível para atender as competências da nossa disciplina (entendida como a construção de um campo de conhecimento com um conjunto de métodos específicos) sem ser em cativeiro nos territórios exclusivos de autonomia? Como explicar a situação que necessariamente atravessa toda a experiência sensorial sem reduzi-la para as diferenças de gênero, étnica ou social? Como responder em nosso estudo, o desafio colocado pelas novas tecnologias?

Palavras-chave: estudos literários; vanguardas; tecnologias; desigualdades; documento

\section{Cómo citar este artículo:}

Bernabé, Mónica. "La cuestión del espacio / en el límite de la literatura". Cuadernos

de Literatura 19. 37 (2015): 328-340. doi:10.11144/Javeriana.CL19-37.cell 
"Brevemente: la materia disminuye;

el proceso de desmaterialización aumenta cada vez más. Perezosas masas de materia son reemplazadas por energía liberada"

Un lugar sin límites es el título de una memorable novela de José Donoso. Un lugar sin límites nombra un espacio difícil de precisar, un territorio indeterminado, que se ofrece a la búsqueda, que se abre a la investigación. Un lugar sin límites remite a la potencia de la literatura que hoy circula traspasando las fronteras discursivas y las formas de recepción que prescriben las disciplinas. ¿Cómo dar cuenta - en el marco de la investigación literaria - de ese flujo incesante, de ese desborde de objetos e incumbencias? Cuando las certezas de los códigos aprendidos se diluyen, es preciso reformular los modos de acceder al conocimiento de la experiencia sensible, para decirlo con el título de otra novela memorable. ¿Será posible atender a los estudios literarios (entendidos como una disciplina que construye un campo de saber con un conjunto de métodos específicos) sin quedar cautivos en los exclusivos territorios de la autonomía? ¿Cómo dar cuenta de la coyuntura que necesariamente atraviesa toda experiencia sensible sin reducirla a diferencias de género, étnicas o sociales? ¿Cómo darle lugar, en los programas de estudio, al desafío que las nuevas tecnologías le presentan a la literatura?

Desde hace un tiempo un sector de la crítica literaria discute sobre la pertinencia o no de la categoría denominada "post-autonomía", se discute sobre el fin de la razón de ser de la noción de campo literario en el sentido en que lo pensó Pierre Bourdieu, se ponen en duda los límites y la especificidad de la literatura. Menos que al temor por el posible fin de la disciplina, la discusión parece responder a un malestar curricular que circula en la universidad como el fantasma de un postergado debate sobre las pertenencias institucionales de los saberes, sobre las atribuciones disciplinares, sobre los alcances teóricos y metodológicos de las prácticas interdisciplinares. La discusión gana en profundidad si le otorgamos dimensión histórica. Esta intervención gira en torno a esa posibilidad. Si entre las dos proposiciones del título de la conferencia he insertado una barra, es con la intención de indicar el corte desde el que funcionan las Relaciones (así, con mayúscula, tal como funciona

1 Las imágenes que ilustran este texto son de El Lissitzky y se puede encontrar la procedencia de las mismas activando el buscador de imágenes de Google. 
en el pensamiento espacializante de Édouard Glissant). Me instalo en la cesura, en el umbral, no como limitación sino como posibilidad para preguntar por el límite de la literatura, por sus extensiones y expansiones.

El planteo tiene su historia. En la nota editorial de Los libros de mayo de 1970, escrita en las aguas turbulentas de la neo-vanguardia argentina, hace casi medio siglo, se anunciaba la "latinoamericanización" de la revista. Para esa época, "latinoamericanizar" era accionar desde un posicionamiento político en favor de la revolución y el compromiso intelectual. ${ }^{2} \mathrm{Al}$ mismo tiempo, la nota editorial examina los criterios desde los cuales habían sido concebidos los números anteriores: si la revista había cometido "errores" ( ic $)$, la causa radicaba en la exagerada utilización de tecnicismos, en la insistencia en una terminología restrictiva que no permitía la incorporación de lectores más allá del círculo cerrado de los especialistas. Y derivado de lo anterior, en lo relativo a la literatura, introduce una mirada crítica hacia los que sostenían que el libro era el lugar donde se insertaban "las obras", cuestionamiento paradójico si se tiene en cuenta que los libros era precisamente el nombre bajo el cual era editada la revista:

Ya se sabe que el formato libro no privilegia ninguna escritura. Es posible que las obras más importantes se estén escribiendo en las noticias periodísticas o en los flashes televisivos. $\mathrm{O}$ en los muros de cualquier parte del mundo. Estos textos, al igual que los libros tradicionales requieren una lectura que descubra su verdad. Los libros se ocupará cuando sea necesario, de los diarios, la televisión, el teatro, la radio, el cine. En este número se habla, por primera vez, de una película. (Schmucler 3).

De este modo, retornaba un debate central de las vanguardias del veinte. En el horizonte se vislumbraba una literatura fuera de la tradición del libro, una literatura más allá de la alta cultura. El tema había sido planteado por Oscar Massotta cuando en 1967 dictaba conferencias y escribía sus ensayos sobre arte y vanguardia para el Instituto Di Tella. "Después del pop: nosotros desmaterializamos" es un texto clave en este sentido. Según Massotta, el arte está estrechamente vinculado a la dimensión tecnológica de lo social y demanda a sus productores una toma de posición frente a las tecnocracias, es decir, a la absorción que los grupos de poder hacen del saber producido socialmente. Los sesenta fueron presentistas, quiero decir, fueron años en que para ser intelectual había que asumir

2 Los tiempos han cambiado. Cuando hoy se dice que Argentina se ha "lationamericanizado" es para aludir al aumento de los porcentajes de pobreza, el deterioro y ausencia del Estado en áreas sensibles como la educación, salud y seguridad. 
una posición en la batalla por la construcción de un saber sobre lo inmediato y accionar por una futura desalienación. Y en medio de la batalla, no es casualidad que Massotta reproduzca fragmentos de un texto de El Lissintzsky ("El futuro del libro" de 1927 traducido por New Left Review en 1967) donde argumentaba sobre la desmaterialización del arte y la literatura. El concepto de "desmaterialización" que el vanguardista ruso concibió desde su experiencia como editor de libros para la revolución, está estrechamente ligado a la aparición de las masas semi-alfabetizadas convertidas en audiencia, y a la descomposición del libro en páginas aisladas y en afiches de diseño. La relación entre escritura e imagen se constituía como fundamento de un proyecto que apuntaba a intensificar el cruce de fronteras entre las disciplinas y los saberes.
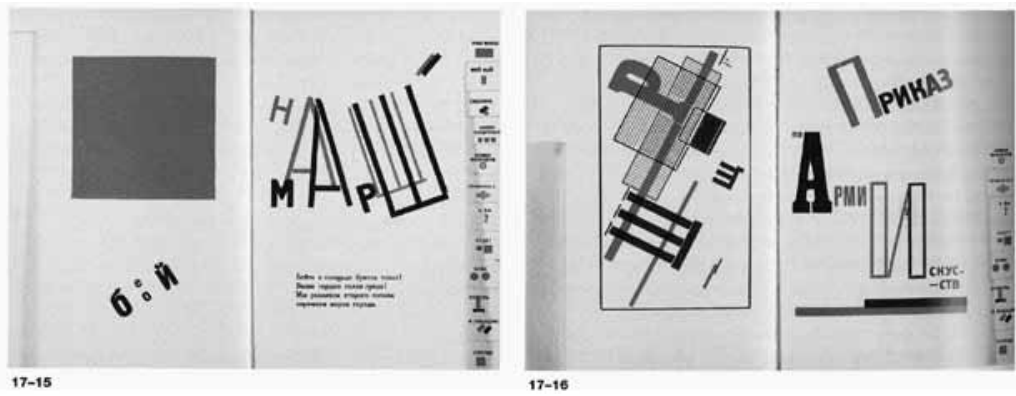

El Lissitzky retorna en los sesenta porque fue la época en que se produjeron enormes transmutaciones en la formas de la literatura en América Latina, particularmente en sus modos de distribución y consumo. ("Centro Editor fuiste más importante que mi padre y que mi/madre y/ en mi juventud estuviste a la altura de Boca Juniors!" dice un poema de Washington Cucurto 24). Si las vanguardias trabajaron sobre una serie de contenidos utópicos, el que insiste y se extiende es el deseo de abolir la frontera entre alta cultura y consumo masivo. La barra del título de esta charla, precisamente, hace referencia a esta dimensión tecnológica de la literatura y el arte sobre la que la modernidad operó la "Gran División", noción crítica que introduce Andreas Huyssen para argumentar sobre las relaciones ocultas entre arte, tecnología y cultura de masas. Desde mediados del siglo diecinueve la relación entre industria cultural y alta cultura fue volátil y confusa, pero la emergencia de las vanguardias rusa y alemana trajo aparejado el mayor ataque hacia la autonomía del arte moderno y la exclusión de su otro: el consumismo de la cultura de masas. La creencia en la Gran División - dice Huyssen - con sus derivaciones estéticas, morales y políticas, persiste aún hoy en el ámbito académico (testimonio de la casi absoluta separación institucional de 
los estudios literarios - incluyendo la nueva teoría literaria- de la investigación acerca de la cultura de masas, o de la difundida insistencia en la exclusión de cuestiones éticas o políticas del discurso sobre el arte y la literatura).

Entonces, la revisión de la teoría de la vanguardia, el retorno a sus dilemas, abre las puertas para la reflexión en/sobre el límite de la literatura y la noción de autonomía sin las presiones de la creencia en la Gran División y sus mitos derivados: el de la "originalidad", el de la "autenticidad" para dar ejemplos de los valores burgueses más resistidos por las vanguardias. Traspasar el límite de la literatura, pensar sus relaciones con las artes plásticas, el cine, la fotografía, los imaginarios sociales, los medios masivos (la lista podría ser interminable) no consiste en sumar disciplinas: en la "y" del encuentro se diluye la inestabilidad que desata el pasaje, el tránsito de un lugar a otro. Muy por el contrario, se trata de articular una epistemología del tránsito, de pasajes al otro lado, un tránsito, como diría Michel De Certeau, donde el lugar propio se ensucia por una serie de cuestionamientos: el lugar propio del sujeto del saber con relación al objeto estudiado, el lugar propio de la disciplina en relación con las prácticas sociales, artísticas, literarias.

En un momento de mucha dispersión y pocos consensos sobre los modos más adecuados de abordar nuestro objeto de estudio, resulta interesante pensar en conceptos o definiciones en transición como propone García Canclini desde un punto de vista crítico hacia el estado actual de los Estudios Culturales. De las nociones que enumera me interesan dos que considero los núcleos vitales desde donde partir para poder activar la experiencia sensible: el "asombro" y la "estética". Las dos nociones están íntimamente relacionadas. El asombro, en el sentido de sorpresa, es el dispositivo indispensable para detectar la presencia del arte. Las vanguardias hicieron del asombro un componente central. El asombro acontece cuando nos enfrentamos al plus del estilo. “¿Qué hacer con el excedente de sentido?", pregunta García Canclini, "¿Qué hacer con la densidad semántica no capturada por la estrategia culturalista o sociologizante?". Si ese excedente es una posibilidad de resistencia al mercado, entonces es imperioso que nos ocupemos de él cuidándonos de no recaer en el idealismo estético.
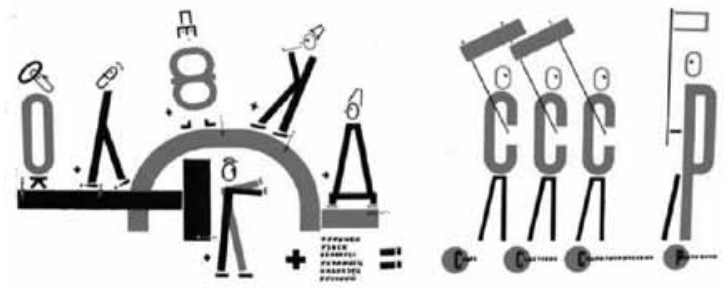
II

"Ya avisaré cuando escriba un libro" avisa María Moreno en el prólogo a la edición chilena de una antología donde reúne ensayos y artículos publicados en periódicos, revistas, suplementos culturales entre 1982 y 2012. Treinta años de escritura desde un lugar excéntrico al campo de la literatura la llevan a afirmar: "En suma, soy periodista" (Teoría 13). Sin embargo, nos cuesta creerle. Periodista sui géneris. Periodista, sí, pero... con una apuesta estética singular. Podríamos decir que María Moreno es un "caso", un "ejemplar" de una práctica de la literatura a distancia del patriarcado de las letras y de una práctica periodística al margen de las informaciones de la primera plana. Desde esta doble "media" pertenencia y/o media exclusión, se sitúa en la indeterminación de un espacio singular, una suerte de No man's land de los campos en disputa. Ese lugar en el que van a parar los inclasificables que escriben al margen de la noción de "obra" y de "libro": "Creo que lo único que he escrito de mi 'obra' ha sido mi seudónimo, compuesto por mi primer nombre legal y el apellido de mi hijo, aunque ocasionalmente estuve casada con un Moreno" (Teoría 13). Manifiesto programático elaborado a partir de la extrañeza con la que practica su identificación fuera de las normas del registro civil, también fuera de las demandas del mercado literario que premia al feminismo políticamente correcto en la figura de "la mujer-escritora".

Parto del ejemplo de María Moreno para referirme a las escrituras que funcionan desagregadas del sistema literario, que circulan en los márgenes del campo y que desde hace unos años la crítica académica viene incorporando a su corpus de trabajo bajo la denominación de "crónica", es decir, adscribiéndolos a la serie literaria dentro del género propio de los inicios de modernidad en América Latina; en otras palabras: a una coyuntura absolutamente distinta a la de inicios del siglo XXI. La confusión tal vez proviene del hecho de que escritores como María Moreno, Carlos Monsiváis y Pedro Lemebel reciclan, para un uso contemporáneo, algunas de las estrategias que los modernistas de fines de siglo XIX utilizaron para la construcción de la imagen de artista y la formación de un público lector: el despliegue de un estilo de escritor en el seno del periódico junto con un toque "raro" en la autofiguración que sigue funcionando como provocación. Será por eso que sus escrituras pueden entrar, aunque ajustadamente, en el saco de esa categorización. Sin embargo, es preciso anotar las diferencias, la más notable: la fabulación de una voz entre plebeya y poética como estrategia de escritura que les posibilita dialogar con los otros. "Escritores que escribiendo -dice Moreno- dan que hablar y hacen hablar para después escribir".

Pero si nos permitimos insistir con las coyunturas es porque ponen en evidencia la distancia entre las prácticas de los cronistas del modernismo y las formas 
narrativas de los escritores contemporáneos. Entre ellos se extiende, además de un siglo, un modo muy diferente de entender la literatura y un abismo tecnológico que es necesario considerar. Nos interesa el contraste porque permite resaltar justamente la diferencia sustancial que existe entre la batalla por la autonomía (por la especificidad propia de los inicios de la modernidad literaria en América Latina) y el actual proceso de desagregación de escrituras en el marco de desclasificación de las tradicionales categorías simbólicas desde las cuales se funda nuestra disciplina. Si faltan mapas confiables para analizar el lugar que ocupan la literatura y las artes en estos tiempos de desbordes de la modernidad, se impone, entonces, estudiar los fenómenos insertos en las relaciones que rodean a esas prácticas discursivas y a los acontecimientos que las determinan. En definitiva, es de urgencia atender no solo al funcionamiento del sistema hacia el interior del campo, sino también ponerlo en relación con la crisis del sistema educativo, en particular en el área de las humanidades y las ciencias sociales. Para decirlo con Stuart Hall:

El fondo de todo esto es un sentido de malestar e incertidumbre que sólo puede ser apuntalado por un currículo nacional; con los enormes desplazamientos de una cultura tradicional profundamente centrada y jerárquica que ha sido corroída por la migración, por la fragmentación, por la emergencia de los márgenes, por las luchas de los márgenes para entrar en la representación, por la confrontación de los márgenes con el poder cultural (Hall 26).

Cito a Hall porque interroga sobre el futuro de las humanidades en la coyuntura inglesa de la posguerra y el thatcherismo. La caída del Estado de bienestar y el desmantelamiento del industrialismo en los ochenta lo llevó a formular una serie de preguntas incómodas: ¿quién puede decirse inglés? ¿Cuáles podrían ser las identidades para reclamar en el siglo XXI? "En búsqueda de una respuesta a esa pregunta, - decía - hemos ido a los mares del sur para defender las Malvinas". Precisamente, desde una nación imperial, la cuestión de los imaginarios de pertenencia a un territorio y una lengua resultaban cruciales para reflexionar sobre el destino de las humanidades y el estudio de la literatura. De ahí la decisión de introducir la cuestión del espacio en tanto el lugar de pertenencia para discutir sobre la literatura. Podemos invertir la perspectiva y desde nuestra localidad - esto es- desde los mares del sur, preguntar por la deriva de nuestras identidades en el lapso que va de la Guerra de Malvinas y la posdictadura hasta nuestro presente que son precisamente los años comprendidos por la antología de María Moreno. Treinta años de democracia, treinta años desde la normalización de la universidad, treinta años de crítica literaria que deberían orientar la evaluación de un proceso en el que hemos acumulado una serie de deudas sociales. La caída de la vieja ciu- 
dad letrada y la pérdida de ciudadanía amenazan a las humanidades y a las razones curriculares que organizaban disciplinas como la de los estudios literarios porque las tecnologías y las desigualdades las atraviesan de principio a fin.

Desde esta perspectiva, la noción de "obra" y de "libro" y el debate en torno a los asuntos específicos del campo literario nos lleva a formular una serie de preguntas: ¿cómo estudiar la literatura en su condición diaspórica? ¿Cómo estudiar un objeto que fue desmaterializando y transmutando en energía liberada como profetizaba El Lissitzky en 1927 ¿Cómo se legitiman las prácticas en el marco de este tránsito incesante? ¿Dónde está el principio y dónde está el fin de un campo en continua expansión? Se trata de configurar un corpus por fuera de la creencia de la Gran División. Me refiero a las formas de una narrativa que, más allá de la clasificación y encuadramiento en un tipo genérico, opera desde materiales heterogéneos, algunos de ellos exógenos a la literatura: imágenes fotográficas, registros de voz y vídeo-grabaciones, notas de observaciones, pequeñas narraciones, ensamble de escenas, citas de material documental, citas literarias que se iluminan y complementan de manera recíproca y que finalmente se integran en una composición parecida al montaje vanguardista que encontraba en ese colage una forma alternativa de acceso a lo real. Como decía Siegfried Kracauer a propósito de los materiales que utilizaba para escribir sus notas en el periódico en 1928: los materiales no deben ser "simplemente incorporados" sino que "hay que obligarlos a declarar" (57).
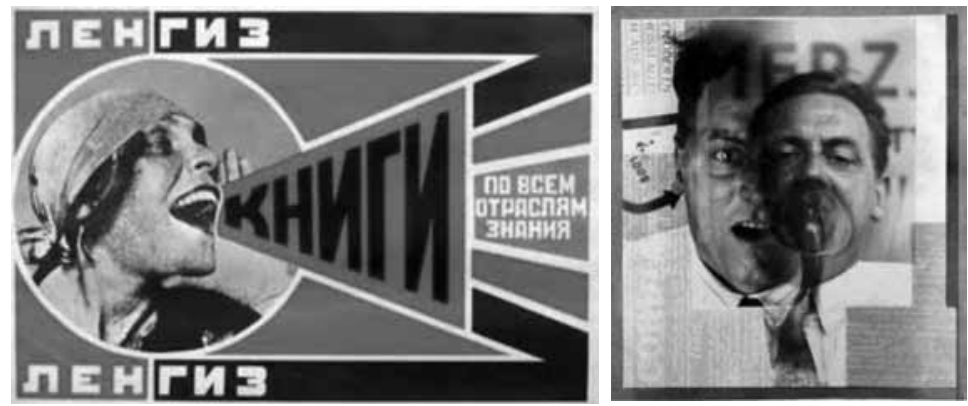

En esta línea de análisis podemos identificar ciertos aspectos que un sector de la crítica viene trabajando a partir de las formas narrativas que se proponen intervenir desafiando las reglas del arte y las taxonomías de la razón disciplinaria. En parte debido a la presencia de lo que podríamos llamar factor documental en el arte y la literatura contemporánea, parece haberse potenciado la relación entre escritura e imagen. Sospechamos que las formas narrativas aún están acusando el impacto que la fotografía y el cine produjeron en la experiencia sensible (la 
mutación antropológica de la que hablaba Barthes) y que, tomando prestados dispositivos de otras esferas, ahondan su exploración desde lo que Jean-Marie Schaeffer llama el "saber de la fotografía" y que Emilio Bernini extendió hacia el cine bajo la noción de "saber documental".

Siguiendo dentro de los dispositivos desarrollados bajo la esfera de lo documental, sería importante pensar en los modos en que la escritura se relaciona con las formas de la oralidad, muchas de las cuales son estudiadas bajo la noción de performance. Son formas de producción y circulación de materiales asociados también a las nuevas tecnologías que desafían la figura tradicional de intelectual moderno. Estas formas priorizan el factor voz, como lo llama María Moreno, aunque poniendo bajo sospecha los habituales modos de representación del otro en América Latina.

Gran parte de los estudios de crítica cultural vienen rediseñando el corpus y reflexionando sobre las metodologías adecuadas para abordar experiencias de escrituras que funcionan como laboratorios de construcción de imaginarios y subjetividades en un continuo proceso de identificación. Desde este aspecto, entonces, la literatura entra en sintonía con los "géneros confusos" como los llamó Clifford Geertz. El ensayo de interpretación cultural junto con ciertas formulaciones etnográficas que postula el arte contemporáneo apuntalan también el factor documental de las escrituras que suelen elegir a las ciudades como el centro de sus indagaciones. El espacio urbano, a su vez, está atravesado por las imágenes. Como dice Jean-Luc Nancy, desde siempre la ciudad y la fotografía se corresponden una con la otra. Además de esta imbricación fundante, ahora los muros son más que nunca un lugar de producción: los graffiti y esténciles del arte callejero construyen las memorias urbanas a través de una suerte de archivo público en las paredes y las plazas. La ciudad-escritura es generadora de "memoria de experiencia", de rastros capaces de traer la presencia de lo ausente, lo abandonado, lo olvidado como citas sesgadas que aportan a la construcción de los relatos de una comunidad, de sus habitantes y de los espacios que articulan nuevas formas de identificación ciudadana.

Habitualmente se cataloga como cronistas a los escritores que experimentan con el factor documental de la literatura contemporánea. Atendiendo a los ejes relacionales local-global y evitando que lo local funcione como un ejemplo o como una mera resistencia a las políticas globales, desde un campo precario, propician la emergencia de espacios de innovación y creación que dinamizan identificaciones parciales y puentes afectivos. Estas escrituras van acompañadas de pequeñas empresas editoriales que apuestan a la edición artesanal o al libro de bolsillo. La Colección Naranja de crónicas ilustradas que edita la Editorial Municipal de Rosario es un caso de gestión y articulación de proyectos de escritura que se destaca por la coherencia de la propuesta y la continuidad en el tiempo. 
El factor documental, insisto, no debe entenderse como una forma de documentar o referirse a lo real, sino como la puesta en funcionamiento de un dispositivo óptico, una suerte de materialismo que remite a una huella efectiva de lo real en el campo perceptivo. En este sentido, Daniel García Helder trabaja en ese registro desde un continuo textual que va de sus anotaciones en los poemas, sus "tomas para un documental" para decirlo con el título de uno de sus proyectos, hasta sus narraciones ilustradas. En La vivienda del trabajador García Helder registra y produce una semiosis de lo urbano a partir de la superposición de tiempos y espacios que conectan pretéritos y presentes, memorias locales activadas a partir de los efectos subjetivos que desata el proceso de reconversión cultural y urbana. De ahí que prefiera instalarse en las fisuras del tiempo, el individual y el colectivo. Su escritura opera con diferentes materiales (archivos, catálogos, fichas de catastro municipal, folletos publicitarios, libros perdidos, instantáneas fotográficas, recorridos urbanos) a fin de establecer una singular conexión con lo real: si la ruina hace visible la caída de un mundo y su suplantación por otro, sus tomas documentales desatan una crítica radical sobre la condición contemporánea del trabajo. García Helder señala, de manera indicial, un espacio enajenado. Se trata de una escritura que se pliega a las estrategias de ficcionalización cinematográfica que Kracauer pensó como un modo de "redimir" a la realidad física. García Helder hace declarar a los materiales. De este modo, al sesgo y sin apelar a la moral, se inscribe el debate sobre el retorno de lo real y los alcances del relato realista en la medida que desmantela la división del trabajo entre la función testimonial de documental y la función estética de la literatura. Su operación es altamente política porque en la era post-industrial pregunta por el trabajo, indaga sobre los rastros de su constitución, sobre las marcas en las prácticas estéticas y en la vida cotidiana de los ciudadanos, y, finalmente, de modo elíptico pero contundente, sienta las bases para un reclamo de justicia efectuado desde la sobrecarga estética de su escritura.

El otro caso que me interesa destacar viene del margen hacia el centro y es el ejercicio poético que las élites barriales de todo el mundo ("cosmopolitismo del pobre" diría Silviano Santiago) ensayan bajo la forma de rap. Son poéticas plebeyas que gestionan figuras de artistas muy diferentes a las de los poetas modernistas, que enuncian y producen en los límites (de la ciudad, de la lengua, del sistema) con y desde las nuevas tecnologías. Fenómenos como los del rap alientan el desarrollo de análisis transdisciplinares para poder atender a la coyuntura pero sin olvidar la innegable dimensión estética del trabajo de sus practicantes. El rap forma parte de la cultura hip hop que tiene mucho para aportar a esta discusión ya que sus prácticas se asientan, sin ocultarse, en la dialéctica entre poesía y cultura de masas. De este modo, desde las zonas más ocultas y desatendidas de la cultura 
popular retorna la pregunta por el rol que desempeña la tecnología en la transformación de la vida cotidiana de los sectores que desde siempre demandaron por su derecho a pertenecer.

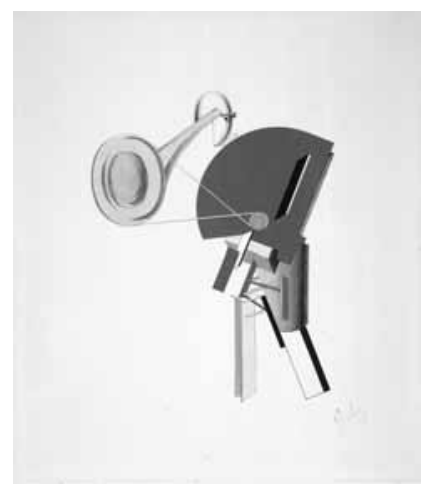

\section{Obras citadas}

Bazin, André. ¿Qué es el cine? Madrid: Rialp, 1999.

Bernabé, Mónica. "Rap: poesía plebeya". alter/nativas. Revista de Estudios Culturales

Latinoamericanos, $\mathrm{n}^{\circ}$ 2, Primavera, 2014, (Online) Ohio State University, USA.

http://alternativas.osu.edu/es/issues/spring-2014/essaysi/bernabe.html

Bernini, Emilio. "Tres ideas de lo documental. La mirada sobre

el otro". Revista Kilómetro 111 marzo 2008. 89-107.

Certeau, Michel de. La invención de lo cotidiano. 1. Artes de

hacer. México: Universidad Iberoamericana, 2000.

Cucurto, Washington. "Los libros del Centro Editor". Como un paraguayo

ebrio y celoso de su hermana. Bahía Blanca: Editorial Vox, 2005. 24.

García Canclini, Néstor. "Definiciones en transición”. Daniel Mato, ed.

Cultura, política y sociedad Perspectivas latinoamericanas. Buenos Aires:

Consejo Latinoamericano de Ciencias Sociales, 2005. 69-81.

García Helder, Daniel. La vivienda del trabajador. Rosario:

Editorial Municipal de Rosario, 2008.

Glissant, Édouard. Tratado del Todo-mundo. Barcelona: Ediciones El Cobre, 2006.

Hall, Stuart. Sin garantías. Trayectorias y problemáticas

en estudios culturales. Lima: IEP, 2010.

Huyssen, Andreas. Después de la gran división. Modernismo, cultura de

masas, posmodernismo. Buenos Aires: Adriana Hidalgo, 2002.

Kracauer, Siegfried. Los empleados. Barcelona: Gedisa, 2008. 
Massotta, Oscar. "Después del pop: nosotros desmaterializamos". Conciencia y Estructura. Buenos Aires: Eterna Cadencia, 2010. 273-303.

Moreno, María. Teoría de la noche. Antología de textos. Santiago de Chile: Universidad Diego Portales, 2011.

—. Subrayados. Buenos Aires: Mar dulce, 2013.

Nancy, Jean-Luc. La ciudad a lo lejos. Buenos Aires: Manantial, 2013.

Santiago, Silviano. "El cosmopolitismo del pobre".

Cuadernos de literatura julio-diciembre 2012.

Schmucler, Héctor, dir. Editorial "Etapa". Revista Los Libros mayo de 1970. 3 .

Schaeffer, Jean-Marie. La imagen precaria del dispositivo

fotográfico. Madrid: Cátedra, 1990. 